\title{
O estatuto da diferença: estruturas infinitesimais e o campo da Comunicação
}

\section{Jamer Guterres de Mello}

Doutor; Universidade Anhembi Morumbi, São Paulo, SP, Brasil

jamermello@gmail.com

SAINT CLAIR, Ericson. Gabriel Tarde e a Comunicação: por um contágio da diferença. Rio de Janeiro: Multifoco, 2012.

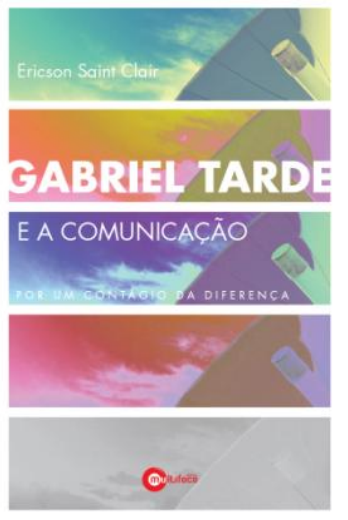

Os cinco capítulos que compõem o livro de Ericson Saint Clair (2012) retomam conceitos do sociólogo francês Gabriel Tarde, procurando mostrar de que forma o estatuto da diferença na sociologia tardeana produz um arcabouço teórico crucial para pensar o campo da Comunicação. Fruto de sua dissertação de mestrado, o livro apresenta os principais pressupostos da obra filosófica de Gabriel Tarde, especialmente a recuperação da monadologia de Leibniz e as estruturas infinitesimais das relações sociais.

Ao contrário da sociologia tradicional - fundada por Émile Durkheim e que aposta em fatos sociais, em representações e em identidades - a sociologia tardeana propõe que os grupos sociais são criações decorrentes das relações de comunicação. A partir disso, Saint Clair desenvolve a hipótese de que o sistema teórico-filosófico de Gabriel Tarde produz uma perspectiva de rediscussão da sociologia tradicional a partir do estudo e da delimitação do infinitamente pequeno (as microengrenagens sociais) que é de suma importância para a Comunicação.

No primeiro capítulo, o autor apresenta as bases teóricas e conceituais da sociologia de Gabriel Tarde, demonstrando de que forma o pensamento sobre a diferença se constitui a partir de uma retomada da monadologia leibniziana. Saint Clair expõe a trajetória de Tarde 
na formulação de uma sociologia da diferença baseada na pura heterogeneidade imanente dos elementos infinitamente pequenos que formam o universo.

No capítulo seguinte, o autor expõe a ligação entre o pensamento da diferença e as similitudes sociais, relação imprescindível para a formulação do conceito de imitação. Pensar a repetição a partir da diferença não significa uma oposição às semelhanças. Pelo contrário, pois a função das similitudes é produzir novas diferenças. Isso acontece, pois, a repetição de dois termos semelhantes acontece sempre de forma imperfeita, já que são sempre dependentes da heterogeneidade radical dos elementos. As repetições produzem similitudes sempre inferiores à potência da heterogeneidade e, assim, são capazes de gerar novas variações, produzindo novas diferenças.

No terceiro capítulo, o conceito de imitação começa a ser trabalhado de forma mais específica, principalmente em função de seus modos de operação: suas leis lógicas e influências extralógicas. São delimitados os duelos lógicos, conflitos internos de crenças e desejos novos e antigos; e as uniões lógicas, quando duas opções de imitação podem ser unificadas para atingir o mesmo objetivo. Já as influências extralógicas da imitação operam em dois sentidos: do interior para o exterior, que seria a forma pela qual acontece a contaminação social; e a imitação do superior pelo inferior, que acontece especificamente entre um indivíduo considerado inferior em relação a outro indivíduo dito superior.

O quarto capítulo apresenta a potência da invenção como conceito fundamental para a sociologia tardeana. A invenção é importante no sentido de garantir que a vida social não seja condenada à organização e à homogeneização, já que os graus de crença e desejo se igualariam caso houvesse apenas o equilíbrio da imitação. A invenção assegura que novas formas de crença e de desejo surjam, cresçam e sejam combinadas fazendo surgir novas descobertas sociais. A imitação é uma espécie de motor imprescindível para a lógica social, possibilitando o aumento das crenças e desejos imanentes.

No capítulo final, o autor retoma a diferença como elemento fundamentalmente comunicacional, em função da variação universal, trabalhando com o conceito de oposição, que em Tarde é fruto da heterogeneidade que produz relações mais complexas que a dialética hegeliana. Aqui, Saint Clair discorre sobre a descoberta de Gabriel Tarde de um poderoso instrumento de variação a partir das diferentes situações de oposição, que seriam repetições inversas, resultados de uma série de variações diferenciais.

Ao longo deste livro, Ericson Saint Clair procura mostrar que o campo da Comunicação está ligado à constituição dos elementos universais a partir do estatuto da 
diferença e, assim, demonstra que a comunicação não é apenas parte do social, mas é o próprio social em movimento. É a partir da retomada da monadologia leibniziana por Gabriel Tarde e a abertura das mônadas garantido a formação de relações de comunicação entre elas que o autor procura evidenciar a importância das estruturas infinitesimais das relações sociais para pensar as Teorias da Comunicação, operando na passagem da transcendência para o campo de imanência. Assim, é possível concluir retomando o grande objetivo de Gabriel Tarde - um autor inexplicavelmente esquecido pelas Ciências Sociais e Humanas durante muitas décadas no século passado - que dizia pertencer à sociologia o estudo das correntes de crença e de desejo no campo social e não o estudo das representações coletivas, como queria Durkheim.

Recebido em 07/07/2016

Aceito em 06/08/2016 